\title{
EI Hábeas Corpus y la exigencia Constitucional de motivar las Resoluciones Judiciales
}

\author{
Havas Corpus and the Constitutional requirement to motivate the Judicial Resolutions
}

Máximo Villarreal Salomé

\begin{abstract}
RESUMEN
Objetivo: Explicar en qué medida las resoluciones judiciales en materia de hábeas corpus, están siendo debidamente motivados por los juzgados penales del Distrito Juridicial de Huaura en el periodo del 2015 al 2017, y cuáles son las causas para que sean motivadas inadecuadamente. Material y Método: El estudio es de tipo descriptivo y analítico. Se analizaron dieciséis (16) sentencias de Habeas corpus tramitados en Huaura y Barranca del distrito Judicial de Huaura. Resultados: De los 16 expedientes analizados, se obtuvo que 10 resoluciones judiciales no están claramente introducidas la pretensión de las partes y la narración de la historia de los hechos;el $50 \%$ de ellos cumplen con la exigencia de motivar debidamente con la justificación interna y la justificación externa; el $70 \%$ de las resoluciones carece de solidez jurisprudencial; y los juzgados penales en un $90 \%$ declaran infundadas e improcedentes las demandas de habeas corpus. Conclusión: Las resoluciones judiciales en materia de hábeas corpus no están siendo motivadas adecuadamente por los jueces penales, lo que configura la afectación a los derechos fundamentales de los demandantes.
\end{abstract}

Palabras claves: Hábeas corpus y motivación de resoluciones judiciales.

\section{ABSTRACT}

Objective: Explain to what extent the judicial resolutions in the matter of habeas corpus are being duly motivated by the criminal courts of the Juridical District of Huaura in the period from 2015 to 2017, and what are the causes for them to be improperly motivated. Material and method: The study is descriptive and analytical. Sixteen (16) habeas corpus sentences processed in Huaura and Barranca of the Huaura judicial district were analyzed. Results: Of the 16 files analyzed, it was obtained that 10 judicial resolutions are not clearly introduced the claim of the parties and the narration of the history of the facts; $50 \%$ of them comply with the requirement to duly motivate with the internal justification and external justification; $70 \%$ of resolutions lack jurisprudential soundness; and $90 \%$ criminal courts declare the claims of habeas corpus unfounded and inadmissible. Conclusion: The judgments in the matter of habeas corpus are not being adequately motivated by the criminal judges, which constitutes the affectation to the fundamental rights of the plaintiffs.

Keywords: The habeas corpus and motivate the judicial resolutions.

\section{INTRODUCCION}

Los derechos constitucionales establecidos en la Constitución Política del Perú, en la jurisprudencia constitucional y en los Tratados Internacionales de Derechos Humanos, cuentan con una protección especial de carácter procesal denominado: procesos constitucionales (proceso de hábeas corpus, proceso amparo y proceso de hábeas data).

El hábeas corpus protege el principio-derecho de la libertad individual y los derechos conexos, se encuentra expresamente establecido en el art. $200^{\circ}$ inc. 1 de la Constitución Política del Perú de 1993 y en la Ley N $^{\circ}$ 28237, Código Procesal Constitucional, que en su art. $25^{\circ}$ señala el conjunto de derechos que protege.

En el Perú el hábeas corpus es utilizado con frecuencia por los justiciables para la defensa de las libertades individuales, frente a las amenazas o vulneraciones provenientes tanto del Estado como de los particulares.

En particular, en el Distrito Judicial de Huaura, las demandas de hábeas corpus contra resoluciones judiciales, son interpuestas por los afectados con el fin de que el órgano jurisdiccional realice el control constitucional o convencional. Según del art. $139^{\circ}$ inc. 6 de la Constitución, los órganos jurisdiccionales (Tribunal Constitucional y el Poder Judicial) tienen la exigencia constitucional de fundamentar debidamente sus decisiones, con el fin de que el justiciable comprenda el itinerario razonamiento que ha realizado el juez, al emitir su decisión. Este principio constitucional, en la práctica, tiene serios problemas de aplicación por parte de los órganos jurisdiccionales al emitir sus decisiones, lo que configuran en ciertas situaciones, graves afectaciones a los derechos fundamentales de la persona.

La investigación tuvo como antecedente en los trabajos realizados por autores peruanos, entre ellos García (1974), que en su tesis doctoral "Hábeas Corpus en el Perú", realizó un diagnóstico de carácter jurídico social del hábeas corpus en el Perú, concluyendo que:

"La jurisprudencia existente en un período de cuarenta años (1933 -1973) demuestra que no hay tendencias estructurales en el desarrollo del Hábeas Corpus. A ello han contribuido una legislación deficiente, un desconocimiento de la institución, la falta de independencia del Poder Judicial, la existencia de las leyes de emergencia que han recortado su uso, y el retraso del país en todos los niveles. (p. 258)."

El trabajo realizado por García (1974), en la década del setenta, ya daban algunas pistas sobre el desconocimiento y el uso inadecuado que se hacía del hábeas corpus en el Perú. Hasta la fecha, han transcurrido más de cuarenta años y los problemas de la época no se han logrado superar en su totalidad.

Otro autor que ha desarrollado el uso del hábeas corpus por los abogados litigantes en el Distrito Judicial de la Libertad en el año 2014 es Mendoza (2017). En su tesis "Hábeas Corpus en la Resolución de Motivación de 
Resoluciones judiciales 2017", concluye:

"Existe un exceso y abuso del derecho de defensa que infringe el deber de actuar de buena fe, los abogados no deben presentar demandas inoficiosas. Los hábeas corpus presentados por los abogados litigantes son declarados infundadas. (p. 150)".

Así mismo, Zelada (2003), en su tesis doctoral titulada "El Hábeas Corpus y las Resoluciones del Tribunal Constitucional", afirma que:

(...) En esta labor se ha podido observar una actitud de rechazo de los jueces a expedientes sobre acciones de garantía. Tal tendencia se refleja en el temor y desagrado ante su simple presentación, agravado por el desconocimiento, por lo que se hace necesario la implementación de cursos permanentes de actualización sobre Derecho Constitucional y Derecho Procesal Constitucional para la adecuada formación de magistrados y abogados (...). (p. 152)

Las investigaciones señaladas anteriormente, dan cuenta que el uso del hábeas corpus por parte de los órganos jurisdiccionales y los justiciables, es inadecuado en la gran mayoría. La razón principal es, porque hay un desconocimiento de la interpretación constitucional de las libertades individuales.

\section{MATERIAL Y MÉTODOS}

Esta investigación es de tipo descriptivo, ,explicativo y analítico. Las técnicas empleadas fueron acopio documental, ficha de investigación y de registros. Los medios utilizados en la investigación fueron dieciséis (16) sentencias de hábeas corpus tramitados en Huaura y Barranca del Distrito Judicial de Huaura, en el que se evaluó su contenido, teniendo en cuenta los siguientes criterios:

- Evaluación de los errores de sintaxis, ortografía y redundancias.

- Evaluación de la descripción clara de los hechos relevantes y la pretensión introducida por el demandante en la demanda.

- Evaluación de la coherencia lógica (motivación interna) y solidez de la argumentación (motivación externa).

- Evaluación de la fundamentación jurídica en el manejo de la jurisprudencia del Tribunal Constitucional peruano y la jurisprudencia internacional.

- Identificar el sentido de las resoluciones judiciales de hábeas corpus (fundada o improcedente), emitidos por los juzgados penales.

\section{RESULTADOS}

El resultado de la investigación desarrollada fue lo siguiente: en primer lugar, una de las causas que incide en la defectuosa e insuficiente motivación de las resoluciones judiciales de hábeas corpus en el Distrito Judicial de Huaura, es el inapropiado uso del lenguaje en la redacción de las sentencias y autos que emiten los juzgados penales de Huaura y Barranca. El efecto inmediato de esta deficiencia es, que las partes en el litigio, se encuentran con serias dificultades en entender con claridad el mensaje del juzgador.
El uso de los adverbios y la sintaxis son inadecuados e innecesarios en más del cincuenta por ciento de los casos estudiados en la presente investigación. La importancia del uso correcto del lenguaje en la decisión judicial es imprescindible porque a través de ella, el juzgador comunica a las partes involucradas en el proceso, respecto del sentido de sus decisiones, sea estimando o desestimando sus pretensiones. Cuando el contenido de una resolución judicial no es entendible, dificulta la comprensión de manera sistemática del receptor, ello trae consigo, cuando las partes que no estén de acuerdo con la decisión judicial tengan que realizar denodados esfuerzos para poder comprender y ejercer los mecanismos de defensa que las normas sustantivas y adjetivas les proveen.

La consecuencia inmediata del uso inadecuado del lenguaje genera desconfianza en la labor del juez. La exigencia constitucional es que toda resolución judicial debe caracterizarse por ser claro en el lenguaje escrito y oral, evitando los tecnicismos o las frases oscuras. En el Estado Constitucional, narrar, escribir y argumentar es imprescindible para una efectiva motivación de las resoluciones judiciales.

En segundo lugar, no se describe con claridad la pretensión de las partes en la resolución judicial, en la parte introductoria de la sentencia no se introduce con claridad la pretensión de las partes y la enunciación de los hechos y circunstancias objeto de la discusión. De las dieciséis (16) resoluciones judiciales materia de estudio, se observa que en diez de ellos, no están claramente introducidas la pretensión de las partes y la narración de la historia de los hechos. Solo en seis sentencias está claramente establecidas la pretensión de las partes.

Estos hechos demuestran no solo la afectación al derecho a una tutela judicial efectiva por parte de los jueces y tribunales, sino también, a recibir resoluciones debidamente motivadas. En ese sentido, el lenguaje jurídico utilizado por el juzgador no es claro. No hay que olvidar que la resolución judicial es una comunicación, mediante el cual no solo las partes en el litigio, sino también, el ciudadano se informa y comprende sobre su contenido. En todas las sentencias estudiadas, los demandantes han sido personas que no tienen formación jurídica, pese a ello, dichas resoluciones no tienen la claridad y rigor para que puedan entender con facilidad el mensaje.

En tercer lugar, solo el cincuenta (50\%) de las resoluciones judiciales analizadas cumple con la observancia debida de las reglas lógicas, es decir, cumplen con la exigencia de motivar debidamente, con la justificación interna y la justificación externa. Así mismo, ocho resoluciones tienen deficiencias lógicas en su fundamentación, no explican en su razonamiento el juicio lógico interno seguido en sus razonamientos, es más, la argumentación que realizan no es integral (justificación interna). Por otro lado, no valoran en su totalidad los medios de prueba presentados por las partes y la interpretación que realizan sobre los derechos fundamentales no es acorde con los principios de razonabilidad y proporcionalidad (justificación interna). El cincuenta por ciento de las resoluciones materia de análisis, no están estructuradas y motivadas debidamente. No se respeta la coherencia y el orden secuencial lógico de los hechos, los fundamentos y la decisión.

No cumplen con el estándar de motivación suficiente, lo que dificulta la comprensión jurídica del caso. 
En cuarto lugar, solo cinco de las dieciséis resoluciones judiciales son debidamente fundamentados conforme a la jurisprudencia del Tribunal Constitucional. Esto demuestra que el $70 \%$ de las resoluciones carecen de solidez jurisprudencial. Con respecto a manejo de la jurisprudencia internacional no existe referencia alguna en las diciséis resoluciones judiciales materia de estudio. Lo que se infiere que en el Distrito Judicial de Huaura y en otros distritos judiciales del Perú existe el mismo problema en el manejo de la jurisprudencia constitucional.

En quinto lugar, en el Distrito Judicial de Huaura (Huaura y Barranca), según los expedientes judiciales, los juzgados penales en un $90 \%$ declaran infundadas e improcedentes las demandas de hábeas corpus, los factores que inciden son precisamente el desconocimiento del rol que cumplen los valores y principios constitucionales en el Estado constitucional. De las dieciséis resoluciones dictadas en materia de hábeas corpus, solo una es declarado fundada y quince declarados infundadas o improcedentes.

\section{DISCUSIÓN}

Los procesos constitucionales se encuentran establecidos en el artículo $200^{\circ}$ de la Constitución, los cuales han sido desarrollados por el Código Procesal Constitucional (Ley 28237) vigente del 01 de diciembre del año 2004. Los cuales se pueden agrupar en dos grupos: a) los procesos constitucionales destinados a proteger las libertades de la persona como hábeas corpus, amparo, hábeas data y acción de cumplimiento, cuya finalidad es proteger el catálogo de los derechos establecidos en el texto constitucional, y b) los procesos constitucionales orgánicos como son el proceso de inconstitucionalidad, acción popular y los conflictos de competencia, previstos en el artículo $200^{\circ}$ y $202^{\circ}$ inciso 3 de la Constitución.

El hábeas corpus pertenece a la especialidad del derecho constitucional. En la Corte Superior de Justicia de Huaura, no hay juzgados constitucionales, solo existen juzgados penales y juzgados civiles. Los juzgados penales se encargan de conocer las demandas de hábeas corpus y los juzgados civiles están a cargo de conocer las demandas de amparo, hábeas data y el de cumplimiento.

En el periodo de nuestra investigación 2015 al 2017, el uso del hábeas corpus por los justiciables para la defensa de sus derechos a la libertad individual y los derechos conexos en el Distrito Judicial de Huaura, va con tendencia a disminuir su uso de manera progresiva.

La exigencia constitucional de la motivación de las resoluciones judiciales, reconocido en la Constitución de 1993, en el Código Procesal Civil y en el Código Procesal Penal, no se cumple a cabalidad en la práctica jurídica.

No hay un modelo metodológico único de motivar las resoluciones judiciales, cada juez trata de fundamentar su decisión a su manera según su saber y entender de las reglas lógicas.

\section{CONCLUSIONES}

Las resoluciones judiciales en materia de hábeas corpus no fueron motivados adecuadamente por los jueces penales en dicho periodo, lo que configura la afectación a los derechos fundamentales de los justiciables.

Las causas que originan la motivación inadecuada son el inadecuado uso de los adverbios en las decisiones; en cuanto a la estructura de la resolución, en la parte introductoria de las sentencias, no se describen con claridad los hechos más relevantes y la pretensión introducida por el demandante. No se respeta la coherencia y el orden secuencial lógico de los hechos y los fundamentos y la decisión. En tercer lugar, en cuanto al manejo de la jurisprudencia del Tribunal Constitucional, es escasa, se ha detectado que en la mayoría de las resoluciones estudiadas hay citas irrelevantes e inadecuadas, y en lo referente al manejo de la normatividad y la jurisprudencia internacional, no hay cita alguna.

\section{REFERENCIA BIBLIOGRÁFICA}

Congreso de la Republica (1993). Constitución Política del Perú.

Decreto Legislativo $N^{\circ}$ 957. (2004). Codigo Procesal Penal. Diario Oficial el Peruano. Lima.

García, D. (1974) El Hábeas Corpus en el Perú, Lima Perú.

Ley N²8237 (2004). Codigo Procesal constitucional. Lima.

Mendoza, F.R.A. (2017) "Hábeas Corpus en la Resolución de Motivación de Resoluciones judiciales en el distrito judicial de la libertad en el año 2014. Tesis para obtener el Titulo profesional de abogado. Universidad Nacional de Trujillo.

Zelada V. (2003). El Hábeas Corpus y las Resoluciones del Tribunal Constitucional.

JURISPRUDENCIA DEL TRIBUNAL CONSTITUCIONAL DEL PERU

- Exp. $\mathrm{N}^{\circ} 3025-2009-\mathrm{PHC} / \mathrm{TC}$.

- EXP. N. ${ }^{\circ} 3467-2005-\mathrm{PHC} / \mathrm{TC}$

- Exp. $\mathrm{N}^{\circ}$ 2663-2003-HC/TC

- EXP. N. ${ }^{\circ} 6253-2006-\mathrm{PHC} / \mathrm{TC}$

- EXP. N. ${ }^{\circ} 4989-2006-P H C / T C$

- EXP. N. ${ }^{\circ} 8787-2006-\mathrm{PHC} / \mathrm{TC}$

- EXP. $\mathrm{N}^{\circ}$ 1230-2002-HC/TC

- EXP. $\mathrm{N}^{\circ}$ 04780-2017-PHC/TC

- EXP. $\mathrm{N}^{\circ}$ 00502-2018-PHC/TC

- EXP. N. ${ }^{\circ} 4107-2004-\mathrm{HC} / \mathrm{TC}$

- EXP. N. ${ }^{\circ}$ 03433-2013-PA/TC

- EXP. N. ${ }^{\circ}$ 3943-2006-PA/TC

- EXP. N. ${ }^{\circ}$ 00728-2008-PHC/TC 